\title{
MIXING RULE CONTAINING REGULAR-SOLUTION AND RESIDUAL EXCESS FREE ENERGY
}

\author{
KIYOFUMI KURIHARA, KATSUMI TOCHIGI AND KAZUO KOJIMA \\ Department of Industrial Chemistry, Nihon University, Tokyo 101
}

Key Words: Thermodynamics, Phase Equilibria, Vapor Liquid Equilibria, High Pressure, Mixing Rule, EOS

\begin{abstract}
A mixing rule is indispensable to the prediction of high-pressure vapor-liquid equilibria by means of the cubic equation of state. This paper proposes a new mixing rule of the energy parameter consisting of terms for geometrical mean of pure energy parameters and the residual part of the excess free energy at infinite pressure.

Also, by using the new mixing rule and the SRK equation, high-pressure vapor-liquid equilibria are correlated with good accuracy for 14 binary systems consisting of non-polar, polar, and associating substances.
\end{abstract}

\section{Introduction}

A mixing rule of the energy parameter in an equation of state is important for prediction of highpressure vapor-liquid equilibria (VLE). Conventionally, the mixing rule that has been widely applied for mixtures consisting of non-polar substances makes use of the geometrical mean of pure energy parameters and the binary interaction parameter. On the other hand, Huron and Vidal's mixing rule ${ }^{7)}$ using the excess free energy at infinite pressure is useful for mixtures containing polar substances.

This paper proposes a new mixing rule for general cubic equations of state, considering that a mixing rule combining the characteristics of both the above would be useful for industrial purposes.

\section{Theory}

To derive the mixing rule for the energy parameter in the cubic equation of state, attention is fixed first on the following equation, in which the molar excess free energy $g^{E}$ is expressed in terms of the sum of the excess free energy obtained for a regular solution $g^{E(\mathbf{R} . \text { Sol) }}$ and the residual part of the excess free energy $\left.g^{E(\operatorname{Res})} \cdot 13,14,15\right)$

$$
g^{E}=g^{E(\mathrm{R} . \mathrm{Sol})}+g^{E(\mathrm{Res})}
$$

Developing Abbott's cubic equation of state and dividing it into a hard sphere term and an attraction term, Eq. (2) is given for general cubic equations of state. ${ }^{1,26)}$

$$
P=\frac{R T(v+\mu)}{(v-b)(v-\tau)}-\frac{\lambda}{(v-\tau)(v-\phi)}
$$

where $\lambda$ is the target mixture energy parameter for this study, and $b, \mu, \tau$ and $\phi$ are mixture parameters which depend on the temperature and the composition of the mixture considered.

The excess free energy $G^{E}$ for $n[\mathrm{~mol}]$ of a mixture is defined by Eq. (3),

$$
G^{E}=H^{E}-T S^{E}=U^{E}+P V^{E}-T S^{E}
$$

where $U^{E}$, the excess internal energy, $V^{E}$, the excess volume, and $S^{E}$, the excess entropy for $n[\mathrm{~mol}]$ of a mixture are given by:

$$
\begin{aligned}
U^{E} & =U-\sum_{i}^{N} n_{i} u_{i} \\
V^{E} & =V-\sum_{i}^{N} n_{i} v_{i} \\
S^{E} & =\left(S-\sum_{i}^{N} n_{i} s_{i}\right)-R \sum_{i}^{N} n_{i} \ln x_{i}
\end{aligned}
$$

$U$, the internal energy, and $S$, the entropy for $n$ [mol] of a mixture in Eqs. (4) and (6) are obtained from Eqs. (7) and (8) using the known pressure-volumetemperature behavior of a mixture.

$$
\begin{aligned}
& U=\int_{V}^{\infty}\left\{P-T\left(\frac{\partial P}{\partial T}\right)_{V, n_{i}}\right\} d V+\sum_{i}^{N} n_{i} u_{i}^{i d} \\
& S=\int_{V}^{\infty}\left\{\frac{n R}{V}-\left(\frac{\partial P}{\partial T}\right)_{V, n_{i}}\right\} d V+R \sum_{i}^{N} n_{i} \ln \frac{V}{n_{i} R T}+\sum_{i}^{N} n_{i} s_{i}^{i d}
\end{aligned}
$$

Substituting Eq. (2) in Eqs. (7) and (8) and applying Eqs. (3) to (6), the molar excess free energy $g^{E}$ is given as follows: 


$$
\begin{aligned}
g^{E}= & \frac{G^{E}}{n}=\frac{\lambda}{\tau-\phi} \ln \left(\frac{v-\tau}{v-\phi}\right)-\sum_{i}^{N} x_{i}\left\{\frac{\lambda_{i i}}{\tau_{i}-\phi_{i}} \ln \left(\frac{v_{i}-\tau_{i}}{v_{i}-\phi_{i}}\right)\right\} \\
& -R T\left[\frac{\mu+b}{b-\tau} \ln (v-b)-\sum_{i}^{N} x_{i}\left\{\frac{\mu_{i}+b_{i}}{b_{i}-\tau_{i}} \ln \left(v_{i}-b_{i}\right)\right\}\right] \\
& +R T\left[\frac{\tau+\mu}{b-\tau} \ln (v-\tau)-\sum_{i}^{N} x_{i}\left\{\frac{\tau_{i}+\mu_{i}}{b_{i}-\tau_{i}} \ln \left(v_{i}-\tau_{i}\right)\right\}\right] \\
& +P v-P \sum_{i}^{N} x_{i} v_{i}
\end{aligned}
$$

In the next step, the excess free energy is derived for a regular solution, defined as a mixture satisfying the following relations: ${ }^{20)}$

$$
S^{E}=0 \quad \text { and } \quad V^{E}=0
$$

For a regular solution, it is assumed that Eq. (11) holds for the mixture energy parameter so that the mixture energy parameter is given by Eq. (12).

$$
\begin{aligned}
& \lambda_{i j}=\left(\lambda_{i i} \lambda_{j j}\right)^{0.5} \\
& \lambda=\sum_{i}^{N} \sum_{j}^{N} x_{i} x_{j} \lambda_{i j}
\end{aligned}
$$

Substituting Eqs. (10) to (12) in Eq. (9), the molar excess free energy for a regular-solution $g^{E(\mathbf{R} \text {.Sol) }}$ is obtained as follows:

$$
\begin{aligned}
g^{E(\mathrm{R} . \mathrm{Sol})}= & \frac{\sum_{i}^{N} \sum_{j}^{N} x_{i} x_{j}\left(\lambda_{i i} \lambda_{j j}\right)^{0.5}}{\tau-\phi} \ln \left(\frac{\sum_{i}^{N} x_{i} v_{i}-\tau}{\sum_{i}^{N} x_{i} v_{i}-\phi}\right) \\
& -\sum_{i}^{N} x_{i}\left\{\frac{\lambda_{i i}}{\tau_{i}-\phi_{i}} \ln \left(\frac{v_{i}-\tau_{i}}{v_{i}-\phi_{i}}\right)\right\} \\
& -R T\left[\frac{\mu+b}{b-\tau} \ln \left(\sum_{i}^{N} x_{i} v_{i}-b\right)\right. \\
& \left.-\sum_{i}^{N} x_{i}\left\{\frac{\mu_{i}+b_{i}}{b_{i}-\tau_{i}} \ln \left(v_{i}-b_{i}\right)\right\}\right] \\
& +R T\left[\frac{\tau+\mu}{b-\tau} \ln \left(\sum_{i}^{N} x_{i} v_{i}-\tau\right)\right. \\
& \left.-\sum_{i}^{N} x_{i}\left\{\frac{\tau_{i}+\mu_{i}}{b_{i}-\tau_{i}} \ln \left(v_{i}-\tau_{i}\right)\right\}\right]
\end{aligned}
$$

Equations (9) and (13) give the molar excess free energy for a mixture and a regular solution, respectively. Substituting Eqs. (9) and (13) into Eq. (1), Eq. (14) is given.

$$
\frac{\lambda}{\tau-\phi} \ln \left(\frac{v-\tau}{v-\phi}\right)=\frac{\sum_{i}^{N} \sum_{j}^{N} x_{i} x_{j}\left(\lambda_{i i} \lambda_{j j}\right)^{0.5}}{\tau-\phi} \ln \left(\frac{\sum_{i}^{N} x_{i} v_{i}-\tau}{\sum_{i}^{N} x_{i} v_{i}-\phi}\right)
$$

$$
\begin{aligned}
& +R T\left\{\frac{\mu+b}{b-\tau} \ln \left(\frac{v-b}{\sum_{i}^{N} x_{i} v_{i}-b}\right)\right. \\
& \left.+\frac{\tau+\mu}{b-\tau} \ln \left(\frac{\sum_{i}^{N} x_{i} v_{i}-\tau}{v-\tau}\right)\right\}+P v-P \sum_{i}^{N} x_{i} v_{i}+g^{E(\mathrm{Res})}
\end{aligned}
$$

Applying the condition of infinite pressure $(P \rightarrow \infty$, $\left.v \rightarrow b, g^{E(\text { Res })} \rightarrow g_{\infty}^{E(\text { Res })}\right)$ and rearranging Eq. (14), the following relation consisting of a term based on a regular solution and a term for the residual part of the excess free energy at infinite pressure is given as the mixing rule for the energy parameter of mixtures.

$$
\begin{gathered}
\lambda=\sum_{i}^{N} \sum_{j}^{N} x_{i} x_{j}\left(\lambda_{i i} \lambda_{j j}\right)^{0.5}-\frac{(\tau-\phi)}{\ln \{(b-\phi) /(b-\tau)\}} \cdot g_{\infty}^{E(\mathrm{Res})} \\
(\tau \neq \phi)
\end{gathered}
$$

If $\tau=\phi$, however, Eq. (16) instead of Eq. (15) is given:

$$
\begin{array}{r}
\lambda=\sum_{i}^{N} \sum_{i}^{N} x_{i} x_{j}\left(\lambda_{i i} \lambda_{j j}\right)^{0.5}-(b-\phi) \\
\cdot g_{\infty}^{E(\text { Res })} \\
(\tau=\phi)
\end{array}
$$

To derive Eqs. (15) or (16), mixture size parameter $b$ has been expressed by Eq. (17).

$$
b=\sum_{i}^{N} x_{i} b_{i}
$$

\section{Correlation of High-Pressure Vapor-Liquid Equilibria}

To confirm the applicability of the new mixing rule, high-pressure VLE are correlated by the SoaveRedlich-Kwong (SRK) equation ${ }^{24)}$ for 14 binary systems consisting of carbon dioxide, hydrogen, nitrogen and $n$-paraffins as non-polar substances, and acetone, water, ammonia, methanol and ethanol as polar and associating substances.

The new mixing rule of the energy parameter is expressed by substituting the mixture parameters shown in Table 1 into Eqs. (15) or (16). For the SRK equation, the following mixing rule is given.

$$
a=\sum_{i}^{N} \sum_{j}^{N} x_{i} x_{j}\left(a_{i i} a_{j j}\right)^{0.5}-\frac{\sum_{i}^{N} x_{i} b_{i}}{\ln 2} \cdot g_{\infty}^{E(\text { Res })}
$$

where $g_{\infty}^{E(\text { Res })}$ is the residual part of the excess free energy at infinite pressure. To express $g_{\infty}^{E(\text { Res })}$, the following Redlich-Kister equation ${ }^{22)}$ is applied:

$$
\begin{aligned}
g_{\infty}^{E(\text { Res })}= & R T x_{1} x_{2}\left\{A+B\left(x_{1}-x_{2}\right)\right. \\
& +C\left(x_{1}-x_{2}\right)^{2}+D\left(x_{1}-x_{2}\right)^{3}+E\left(x_{1}-x_{2}\right)^{4} \\
& \left.+F\left(x_{1}-x_{2}\right)^{5}+\cdots\right\}
\end{aligned}
$$


Table 1. Parameters in Eqs. (2) to (17)

\begin{tabular}{lccccc}
\hline Equation of state & $b$ & $\lambda$ & $\mu$ & \multicolumn{1}{c}{$\phi$} \\
\hline Soave-Redlich-Kwong $^{24)}$ & $b$ & $a$ & 0 & 0 & $-b$ \\
Peng-Robinson $^{19)}$ & $b$ & $a$ & $(1+\sqrt{2}) b$ & $-(1+\sqrt{2}) b$ & $-(1-\sqrt{2}) b$ \\
Martin $^{12)}$ & $b$ & $a$ & $c$ & $-c$ & $-c$ \\
Ishikawa-Chung-Lu $^{8)}$ & $b$ & $a / T^{0.5}$ & $b$ & 0 & $-2 b$ \\
Pater-Teja $^{18)}$ & $b$ & $a$ & $c$ & $-c$ & $-b$ \\
\hline
\end{tabular}

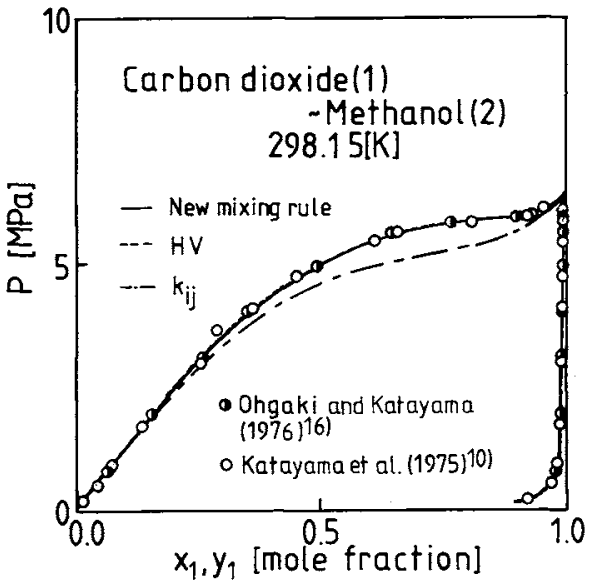

Fig. 1. Correlated results of vapor-liquid equilibria for the carbon dioxide-methanol system.

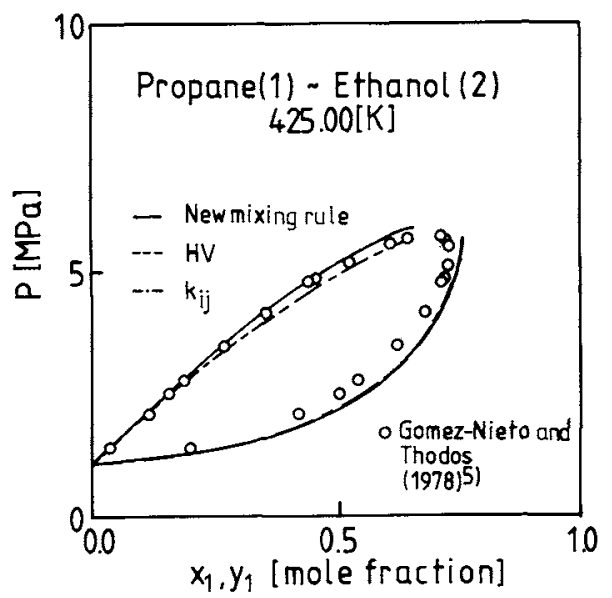

Fig. 2. Correlated results of vapor-liquid equilibria for the propane-ethanol system.

The number of parameters in Eq. (19) is adjusted to obtain exact results for each system. Table 2 shows the correlated results given by using the new mixing rule. Table 2 also shows the results given by the conventional mixing rule containing the binary interaction parameter $k_{i j}$ and by Huron and Vidal's mixing rule. As an example, the correlated results for the systems carbon dioxide-methanol $(298.15 \mathrm{~K}),{ }^{10,16)}$ propane-ethanol $(425.00 \mathrm{~K}){ }^{5)}$ hydrogen-nitrogen $(83.67 \mathrm{~K})^{25)}$ and methane- $n$ hexadecane $(542.65 \mathrm{~K})^{11)}$ and shown in Figs. 1 to 4.

When high-pressure VLE are correlated by Huron

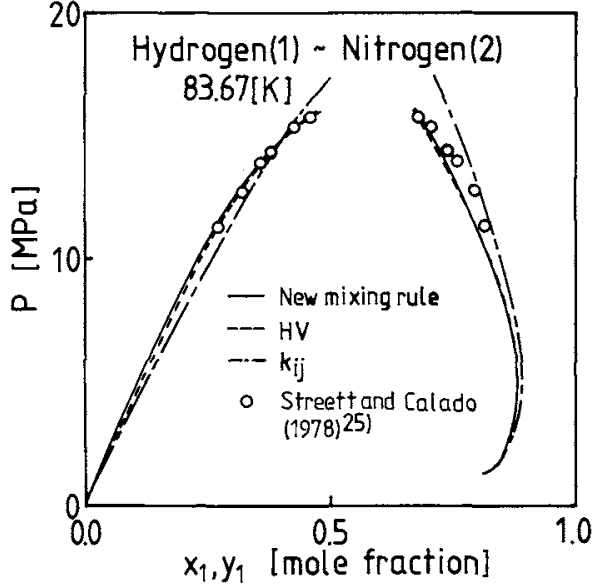

Fig. 3. Correlated results of vapor-liquid equilibria for the hydrogen-nitrogen system.

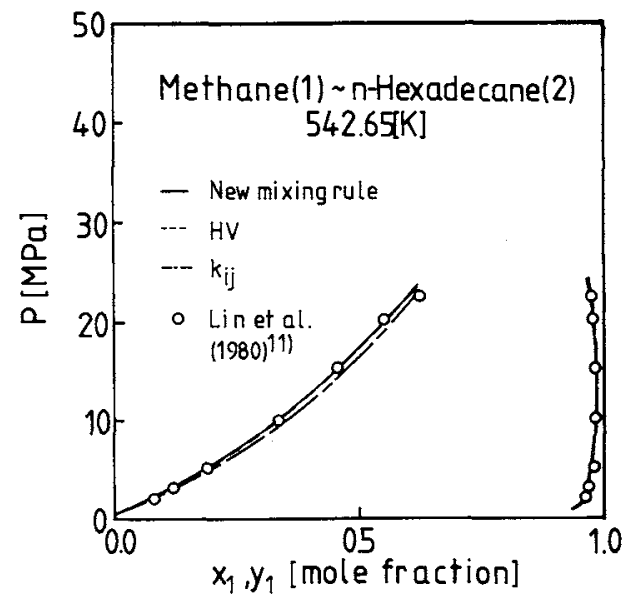

Fig. 4. Correlated results of vapor-liquid equilibria for the methane- $n$-hexadecane system.

and Vidal's mixing rule, the excess free energy at infinite pressure is evaluated by the Redlich-Kister equation which is expressed by Eq. (19). The pure component parameters of the SRK equation are obtained from the generalized equation ${ }^{24)}$ using critical temperature, critical pressure, and the acentric factor. ${ }^{22)}$

From Table 2, it is evident that the new mixing rule gave better results than the conventional mixing rule using the binary interaction parameter, and slightly better results than Huron and Vidal's mixing rule. 
Table 2. Correlated results of high-pressure vapor-liquid equilibria for binary systems by applying the new mixing rule, Huron and Vidal's mixing rule (HV) and the conventional mixing rule $\left(k_{i j}\right)$

\begin{tabular}{|c|c|c|c|c|c|c|c|c|c|c|}
\hline \multirow[b]{2}{*}{ System } & \multirow[b]{2}{*}{$T[\mathrm{~K}]$} & \multirow{2}{*}{$\begin{array}{l}\text { Pressure } \\
\text { range } \\
\text { [MPa] }\end{array}$} & \multirow[b]{2}{*}{$n$} & \multicolumn{2}{|c|}{ New mixing rule } & \multicolumn{2}{|l|}{$H V$} & \multicolumn{2}{|c|}{$k_{i j}$} & \multirow[b]{2}{*}{ Lit. } \\
\hline & & & & $\begin{array}{l}A \\
B \\
C\end{array}$ & $\begin{array}{l}|\Delta P / P| \\
a v .(\%)\end{array}$ & $\begin{array}{l}A \\
B \\
C\end{array}$ & $\begin{array}{l}|\Delta P / P| \\
a v .(\%)\end{array}$ & $k_{12}$ & $\begin{array}{l}|\Delta P / P| \\
a v .(\%)\end{array}$ & \\
\hline $\begin{array}{l}\text { Ethane } \\
\text {-acetone }\end{array}$ & 298.15 & $0.48-3.97$ & 8 & $\begin{array}{l}1.448 \\
0.4216 \\
0.0\end{array}$ & 1.71 & $\begin{array}{l}1.612 \\
0.4615 \\
0.0\end{array}$ & 1.81 & 0.1341 & 3.22 & 17 \\
\hline $\begin{array}{l}\text { Ethane } \\
\text {-methanol }\end{array}$ & 298.15 & $1.09-4.12$ & 5 & $\begin{array}{c}0.2336 \\
-0.003965 \\
0.1864\end{array}$ & 1.33 & $\begin{array}{c}1.853 \\
-0.05520 \\
0.1184\end{array}$ & 1.79 & 0.0163 & 5.55 & 17 \\
\hline $\begin{array}{l}\text { Propane } \\
\text {-acetone }\end{array}$ & 400.00 & $1.39-4.20$ & 4 & $\begin{array}{l}0.4602 \\
0.4394 \\
0.0\end{array}$ & 0.72 & $\begin{array}{l}0.5912 \\
0.4522 \\
0.0\end{array}$ & 0.72 & 0.0638 & 4.88 & 5 \\
\hline $\begin{array}{l}\text { Propane } \\
\text {-ethanol }\end{array}$ & 425.00 & $1.03-5.68$ & 13 & $\begin{array}{l}0.09908 \\
0.2400 \\
0.0\end{array}$ & 1.15 & $\begin{array}{l}0.6325 \\
0.1868 \\
0.0\end{array}$ & 1.29 & 0.0109 & 3.09 & 4 \\
\hline $\begin{array}{c}\text { Carbon dioxide } \\
\text {-methanol }\end{array}$ & 298.15 & $0.22-5.95$ & 21 & $\begin{aligned} & 0.4466 \\
& 0.2955 \\
& 0.05795 \\
D=- & 0.01373 \\
E= & 0.5246 \\
F= & 0.4534\end{aligned}$ & 0.94 & $\begin{aligned} & 1.010 \\
& 0.4120 \\
& 0.05795 \\
D=- & 0.03233 \\
E= & 0.5132 \\
F= & 0.4445\end{aligned}$ & 0.98 & 0.0336 & 4.56 & 10,16 \\
\hline \multirow[t]{2}{*}{$\begin{array}{c}\text { Ammonia } \\
\text {-water }\end{array}$} & 353.15 & $0.05-0.17$ & 8 & $\begin{array}{c}-4.186 \\
-0.5671 \\
0.0\end{array}$ & 1.65 & $\begin{array}{c}-2.453 \\
-0.8058 \\
0.0\end{array}$ & 1.71 & -0.2700 & 6.85 & 2 \\
\hline & 363.15 & $0.08-0.14$ & 7 & $\begin{array}{c}-5.366 \\
-2.174 \\
0.0\end{array}$ & 1.87 & $\begin{array}{c}-3.180 \\
-1.828 \\
0.0\end{array}$ & 1.77 & -0.2443 & 4.86 & 2 \\
\hline $\begin{array}{l}\text { Methanol } \\
\text {-water }\end{array}$ & 373.15 & $0.10-0.34$ & 16 & $\begin{array}{r}-1.321 \\
0.3318 \\
-0.4034\end{array}$ & 1.45 & $\begin{array}{r}0.7916 \\
-0.4984 \\
-0.1093\end{array}$ & 1.38 & -0.0805 & 3.37 & 8 \\
\hline $\begin{array}{c}\text { Carbon dioxide } \\
-n \text {-decane }\end{array}$ & 510.93 & $1.38-15.33$ & 10 & $\begin{array}{l}0.5290 \\
0.2752 \\
0.0\end{array}$ & 1.30 & $\begin{array}{l}0.6225 \\
0.3430 \\
0.0\end{array}$ & 1.62 & 0.1833 & 2.80 & 21 \\
\hline $\begin{array}{l}\text { Hydrogen } \\
\text {-propane }\end{array}$ & 173.15 & $0.23-20.68$ & 8 & $\begin{array}{l}0.05114 \\
-0.1866 \\
0.0\end{array}$ & 1.69 & $\begin{array}{l}1.754 \\
0.2715 \\
0.0\end{array}$ & 1.70 & 0.0811 & 2.59 & 27 \\
\hline $\begin{array}{l}\text { Hydrogen } \\
\text {-nitrogen }\end{array}$ & 83.67 & $11.27-15.68$ & 6 & $\begin{array}{c}0.1488 \\
-0.2093 \\
0.0\end{array}$ & 0.43 & $\begin{array}{l}1.299 \\
-0.009000 \\
0.0\end{array}$ & 0.51 & 0.0167 & 3.38 & 25 \\
\hline $\begin{array}{l}\text { Nitrogen } \\
\quad-n \text {-pentane }\end{array}$ & 310.71 & $0.25-20.75$ & 14 & $\begin{array}{c}0.2745 \\
-0.001939 \\
0.0\end{array}$ & 1.81 & $\begin{array}{l}0.7240 \\
0.1604 \\
0.0\end{array}$ & 1.83 & 0.1037 & 3.48 & 9 \\
\hline $\begin{array}{l}\text { Methane } \\
\quad-n \text {-octane }\end{array}$ & 293.15 & $7.09-28.37$ & 9 & $\begin{array}{c}-0.8842 \\
1.224 \\
-0.6359\end{array}$ & 1.09 & $\begin{array}{c}-0.8461 \\
1.222 \\
-0.6037\end{array}$ & 1.09 & 0.0095 & 10.95 & 28 \\
\hline $\begin{array}{l}\text { Methane } \\
\quad-n \text {-hexadecane }\end{array}$ & 542.65 & $2.08-22.55$ & 7 & $\begin{array}{l}0.08648 \\
0.1324 \\
0.0\end{array}$ & 1.19 & $\begin{array}{l}0.08459 \\
0.1341 \\
0.0\end{array}$ & 1.19 & 0.0351 & 2.89 & 11 \\
\hline $\begin{array}{l}\text { Ethane } \\
\quad-n \text {-heptane }\end{array}$ & 449.82 & $2.76-8.27$ & 14 & $\begin{array}{l}0.1334 \\
0.2473 \\
0.0\end{array}$ & 0.80 & $\begin{array}{l}0.1351 \\
0.2423 \\
0.0\end{array}$ & 0.84 & 0.0486 & 2.04 & 3 \\
\hline \multicolumn{11}{|c|}{$\begin{array}{l}n=\text { No. of data points } \\
A, B, C, D, E, F=\text { Redlich-Kister parameter in Eq. (19) } \\
\text { Huron and Vidal's mixing rule }\end{array}$} \\
\hline
\end{tabular}

\section{Conclusions}

For the energy parameter in the cubic equations of state, a mixing rule containing the geometrical mean of pure energy parameters and the residual part of the excess free energy at infinite pressure was derived. 
This mixing rule was applied to the SRK equation and high-pressure VLE were correlated with good accuracy for 14 binary systems consisting of nonpolar, polar, and associating substances.

\section{Nomenclature}

A = parameter in Redlich-Kister equation

$a \quad=$ energy parameter in SRK equation of state $\quad\left[\mathrm{MPa}\left(\mathrm{m}^{3} / \mathrm{mol}\right)^{2}\right]$

$B \quad=$ parameter in Redlich-Kister equation $[-]$

$b \quad=$ parameter in SRK equation of state or general equation of state $\quad\left[\mathrm{m}^{3} / \mathrm{mol}\right]$

$C, D, E, F=$ parameter in Redlick-Kister equation $\quad[-]$

$G \quad=$ free energy per $n[\mathrm{~mol}]$ of a mixture $\quad[\mathrm{J}]$

$g \quad=$ molar free energy of a mixture $\quad[\mathrm{J} / \mathrm{mol}]$

$g^{E} \quad=$ molar excess free energy $\quad[\mathrm{J} / \mathrm{mol}]$

$g^{E \text { (Res) }} \quad=$ molar residual excess free energy $\quad[\mathrm{J} / \mathrm{mol}]$

$g^{E(\mathbf{R} . \mathrm{Sol})}=$ molar excess free energy obtained for a regular solution

$H \quad=$ enthalpy per $n[\mathrm{~mol}]$ of a mixture

$k_{i j} \quad=$ binary interaction parameter

$N=$ number of components

$=$ number of moles

$=$ pressure

$=$ gas constant

$=$ entropy per $n[\mathrm{~mol}]$ of a mixture

$=$ molar entropy of a mixture

$=$ temperature

$=$ internal energy per $n$ [mol] of a mixture

$=$ molar internal energy of a mixture

$=$ volume per $n[\mathrm{~mol}]$ of a mixture

$=$ molar volume of a mixture

$=$ mole fraction

$\hat{\lambda}=\begin{aligned} & \text { energy parameter in general cubic equation } \\ & \text { of state } \quad\left[\mathrm{MPa}\left(\mathrm{m}^{3} / \mathrm{mol}\right)^{2}\right]\end{aligned}$

$\hat{\lambda}=$
of state

$\hat{\lambda}=$
of state
$\begin{aligned} & \text { energy parameter in general cubic equation } \\ & {\left[\mathrm{MPa}\left(\mathrm{m}^{3} / \mathrm{mol}\right)^{2}\right]}\end{aligned}$

$\mu, \tau, \phi \quad=$ parameter in general cubic equation of state

$\left[\mathrm{m}^{3} / \mathrm{mol}\right]$

$\langle$ Subscripts〉

$1,2, i, j=$ molecule $1,2, i$, and $j$

$\infty \quad=$ infinite pressure

$\langle$ Superscripts $\rangle$

$E \quad=$ excess property

id $\quad=$ ideal gas condition

\section{Literature Cited}

1) Abbott, M. M.: "Advances in Chemistry Series," 182, p. 47, American Chemical Society, Washington, D. C. (1979).

2) Clifford, I. L. and I. E. Hunter: J. Phys. Chem., 37, 101 (1933).

3) Dastur, S. P.: Ph. D. Dissertation, Northwestern Univ. (1964).

4) Gomez-Nieto, M. and G. Thodos: AIChE J., 24, 672 (1978).

5) Gomez-Nieto, M. and G. Thodos: Chem. Eng. Sic., 33, 1589 (1978).

6) Griswold, J. and S. Y. Wong: Chem. Eng. Prog. Symp. Ser., 48, 18 (1952).

7) Huron, M. J. and J. Vidal: Fluid Phase Equilibria, 3, 255 (1979).

8) Ishikawa, T., W. K. Chung and B. C.-Y. Lu: AIChE J., 26, 312 (1980).

9) Kalra, H., D. B. Robinson and G. J. Besserer: J. Chem. Eng. Data, 22, 215 (1977).

10) Katayama, T., K. Ohgaki, G. Maekawa, M. Goto and T. Nagano: J. Chem. Eng. Japan, 8, 89 (1975).

11) Lin, H.-M., H. M. Sebatian and K.-C. Chao: J. Chem. Eng. Data, 25, 252 (1980).

12) Martin, J. J.: Ind. Eng. Chem. Fundam., 18, 81 (1979).

13) Mollerup, J.: Fluid Phase Equilibria, 15, 189, 381 (1983).

14) Nitta, I. and T. Katayama: J. Chem. Eng. Japan, 7, 381 (1974).

15) Novak, J. P., P. Vonka, J. Suska, J. Matous and J. Pick: Collect. Czech. Chem. Commun., 39, 3593 (1974).

16) Ohgaki, K. and T. Katayama: J. Chem. Eng. Data, 21, 53 (1976).

17) Ohgaki, K., F. Sano and T. Katayama: $J$. Chem. Eng. Data, 21, 55 (1976).

18) Patel, N. C. and A. S. Teja: Chem. Eng. Sci., 37, 463 (1982)

19) Peng, D.-Y. and D. B. Robinson: Ind. Eng. Chem. Fundam., 15, 59 (1976)

20) Prausnitz, J. M.: "Molecular Thermodynamics of Fluid-Phase Equilibria," p. 263, Prentice-Hall, New Jersey (1969).

21) Reamer, H. H. and B. H. Sage: J. Chem. Eng. Data, 8, 508 (1963).

22) Redlich, O. and A. T. Kister: Ind. Eng. Chem., 40, 345 (1948).

23) Resid, R. C., J. M. Prausnitz and T. K. Sherwood: "The Properties of Gases and Liquids," p. 629, McGraw-Hill, New York (1977).

24) Soave, G.: Chem. Eng. Sci., 37, 1197 (1972).

25) Streett, W. B. and J. C. G. Calado: J. Chem. Thermodynamics, 10, 1089 (1978).

26) Sugie, H. and K. Arai: Kagaku Kōgaku, 48, 727 (1984).

27) Trust, D. B. and F. Kurat: AIChE J., 17, 86 (1971).

28) Welikowakij, A. S., G. S. Stepanowa and J. I. Wybornowa: Gazowaja Prom., Moskwa, 9, 1 (1964). 